\title{
Correction to: An analysis of the ecological components within a text structure intervention
}

\author{
Andrea L. Beerwinkle ${ }^{1}$. Kausalai Wijekumar ${ }^{1}$. Sharon Walpole ${ }^{2}$. \\ Rachael Aguis ${ }^{3}$
}

Published online: 4 January 2021

(c) Springer Nature B.V. 2021

\section{Correction to: Read Writ (2018) 31:2041-2064 https://doi.org/10.1007/s11145-018-9870-5}

In the original publication of the article the funding information was missed to be published. The funding information has been included in this correction.

Funding The research reported here was supported by the Institute of Education Sciences, U.S. Department of Education, through Grants R305A150057 to Texas A\&M University. The opinions expressed are those of the authors and do not represent views of the Institute or the U.S. Department of Education.

Publisher's Note Springer Nature remains neutral with regard to jurisdictional claims in published maps and institutional affiliations.

The original article can be found online at https://oi.org/10.1007/s11145-018-9870-5.

Andrea L. Beerwinkle

abeerwinkle@tamu.edu

1 Department of Teaching, Learning, and Culture, Texas A\&M University, 308 Harrington Tower, College Station, TX 77843, USA

2 School of Education, University of Delaware, Newark, DE, USA

3 University of Malta, Msida, Malta 